\title{
PROMOTING PSYCHOSOCIAL LIFE OF PERSONS WITH EPILEPSY
}

Dr. Prakashi Rajaram*, Ms. Shreedevi A.U.** and Ms. Preeti Bhatkhande***

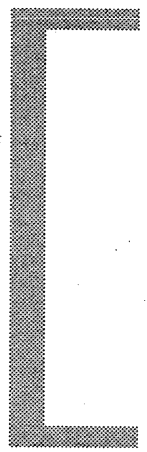

\begin{abstract}
Epilepsy is a long-standing, disabling illness, which has various psychosocial implications for people who suffer from it. This article reviews literature on the psychosocial aspects of epilepsy. The psychosocial aspects reviewed are with specific reference to certain factors like: family, children, marriage, employment and quality of life. The article also presents a brief review on the psychosocial interventions and suggests further interventions to help persons suffering from epilepsy.
\end{abstract}

Epilepsy is a disorder of the central nervous system, specifically the brain. Our nervous system is a communication network that controls every thought, emotion, impression, memory and movement, essentially defining who we are. Nerves throughout the body function like telephone lines, facilitating the brain to communicate with every part of the body via electrical signals. In epilepsy, the brain's electrical rhythms have a tendency to become imbalanced, resulting in recurrent seizures.

* Assistant Professor, Psychiatric Social Work

** Psychiatric Social Work Consultant

*** M.Phil Scholar, Department of Psychiatric Social Work, NIMHANS, Bangalore 
Epileptic seizures are divided into 3 major classes.

I Partial seizures

II General seizures

III Unclassified epileptic seizures

- Reflex epilepsy

- Non epileptic attacks etc

Epilepsy constitutes major public health problems across the world. A neuroepidemiological study by Gouri Devi et al (1987) in semi-urban and rural areas of South India found prevalence of epilepsy as $463 / 1,00,000$ and $248 / 1,00,000$ respectively. A multi-center study on severe mental morbidity (ICMR, 1987) conducted in India found the prevalence of epilepsy to be $7.8 / 1000$ population. On projection of this figure it can be estimated that there are 45 to 75 million persons with epilepsy in our country. In India 5 / 1000 have more than one attack of epilepsy. Education material by Indian Epilepsy Association (1992) says 1 in 20 persons have at least one febrile seizure in their lives.

The problems that patients with epilepsy go through vary from interpersonal and emotional adjustments, family coping, adjustment within marital relationship, issues surrounding children, employment, economic burden, and stigma in being on treatment for long period and that exist in the society around epilepsy. Possibly the least understood and more neglected aspects of epilepsy are the social, psychological and behavioural problems that are so common. While medical disciplines focus on the neurological problems per se, the psychosocial disciplines, especially the social work professionals deal with the associated problems of interpersonal and social issues.

Social work professionals insist that in order to analyze and understand an individual with epilepsy, it is necessary to look into "person-in-situation" configuration. This process of understanding called as 'social study' propounds that while arriving at any conclusion about an individual, a detailed in-depth analysis of the person and the situation the person exists in should be understood - the situation being family, neighbourhood, community, social environment and the state of being ill. All these affect an individual and the individual also influences some change on the situation. This 'psychosocial approach' is used extensively in the contemporary social work practice.

Professional social work services for neurologically ill are relatively new field in India. However, a considerable number of neurological departments, especially cities like Bombay, Bangalore, Delhi and Chennai have included clinical social workers, some are involved with Epilepsy Clinic and others are working in different action oriented research projects. 
Although the National Institute of Mental Health and Neuro Sciences, Bangalore, pioneered the unique combination of services, training and research in the field of mental health and neurosciences, many more treatment centers are realizing the need for multidisciplinary approach in offering such services.

The current paper is based on the above rationale and gives an over- view of the main psychosocial issues that are of utmost importance in bringing the life of patients with epilepsy back into effective normalcy.

\section{Psychosocial Life of Persons with Epilepsy:}

Psychosocial adjustment of individuals suffering epilepsy goes through a change as individual's perspective on the illness state and the family's apprehension on the probable risks that $s$ /he could face are likely to throw the coping off balance. Dimensions of this adjustment are many.

\section{Emotional Adjustment:}

Studies conducted in the aspect of emotional adjustment reveal that social isolation and withdrawal are commonly reported in epileptic persons (Ziegler, 1982; Lechtenberg, 1984). Often lack of self-esteem reinforces this pattern, reducing the person's opportunity to learn appropriate social interaction skills (Ozuna, 1979; Woodward, 1982). Furthermore frequent hospitalization may also decrease the opportunities for social interaction. It is found that persons with epilepsy suffer from anxiety about occurrence of seizures and its unpredictable nature. However, a recent study (Mirnics, Halasz, 2001) reveals that factors like self-esteem, cognitive abilities, family expectations, understanding, acceptance, degree of perceived stigma determine the extent to which an individual can cope and emotionally be prepared to accept his/her epilepsy.

As narrated earlier, another aspect of internal adjustment is the adjustment seen in the family.

\section{Family Adjustment:}

The presence of an epileptic person in a family gives rise to many dynamics and reactions among family members. Various studies (Shaw, 1983; Ozuna, 1979; Heisler and Friedman, 1981; Ziegler, 1982; Ford et al., 1983) have recorded a range of familial reactions ranging from overprotection to scapegoating to rejection.

\section{Marriage:}

It is generally agreed that epileptic persons have a lower rate of marriage than persons without epilepsy (Dansky et al., 1980; Batzel and Dodril, 1984). Lechtenberg 
(1984) estimated that $56 \%$ of men with epilepsy and $69 \%$ of women with epilepsy are unmarried. In addition, epileptic persons appear to have a lowered rate of sexual behaviour and more sexual disturbances than do non-epileptic persons (Max, 1984; Lechtenberg, 1984). Thus, literature shows that epilepsy is a great risk to marital life. Saleh-El-Hilu (1990) found that epilepsy has adverse effects on marriage, education, occupation and persons with epilepsy are prone to have social difficulties and their marital status and fertility are far from satisfactory.

Marriage posed a major problem especially in women. It is a source of marital separation, divorce and marital disharmony. When women get this illness they become helpless victims. Similar illness in husbands is tolerated, but the wives were neglected or deserted as soon as the husband came to know about the wife's epilepsy.

\section{Employment:}

Employment is viewed as a very important factor in psychosocial adjustment, the most serious social problem being one of under employment (Gupta, 1981). Elwes (1991) in his study found that $46 \%$ of the epileptics were unemployed, reasons being restriction due to working at heights or near unguarded machinery, inability to hold a driving license, irrational attitudes of the employees, presence of associated handicaps and drug induced drowsiness.

Hatz (1992) found that lack of employment had a negative impact on the quality of life of persons with epilepsy. Employment to people with epilepsy is very important, as employment determines the way of life, social and financial status and the role in society and it is a source of personal satisfaction of social companionship of esteem, of discipline and of purpose. However some literature gives data contrary to the already existing literature. A study by Parthasarthy and Janardhana (2002) showed that in the Indian context a few respondents did not feel difficult to tell employers that they have epilepsy and some did not find it difficult to get a new job because of their attacks!

\section{Stigma, Attitudes towards Epilepsy:}

The stigma faced by people suffering from epilepsy (Baker et al 2000) is well documented. A study on stigma among European countries showed that $51 \%$ of persons with epilepsy reported feeling stigmatized, while $18 \%$ respondents reported feeling highly stigmatized. High scores on stigma measures correlated with negative feelings, worry and anxiety. Another study by Chiou (2001) compared attitudes of teachers in Taiwan towards preschoolers about epilepsy and asthma perception. Results showed that more teachers thought epilepsy was hereditary, not asthma. More than $30 \%$ thought that epilepsy seizures were associated with insanity, not 
asthma. Acceptance of children with epilepsy was significantly lower than children with asthma. Moreover, teachers were worried about objection from other parents in case of epileptic children in the class.

Focusing specially on children suffering from epilepsy, one could identify four areas of concern. They are behavior, development, education and family living. This is demonstrated by literature at length. It is documented that children with epilepsy faced different problems like hyperactivity, mental retardation, behavioral problem, scholastic backwardness and other psychiatric problems in association with epilepsy. Such psychological and psychiatric problems in children make the situation complicated and more stressful for them (Dodrill et al, 1984; Smith et ai, 1991; Collings, 1992). Stress and emotional agitation experienced by children with epilepsy can precipitate the onset or increase the frequency of seizures, which in turn leads to school drop-out and because of discontinuation of studies they spend time remaining idle at home.

\section{Children:}

There is also evidence that significant number of children with epilepsy are underachievers in certain subject areas. They might have problems in reading and to a great extent spelling and arithmetic. In addition, children with epilepsy appear to do less than their peer group in terms of educational and vocational qualifications. School going children have problems in attending school, more often they are not accepted in the classroom and also by the school authorities. The children were too embarrassed to go to school or join the peer group because of their epilepsy (Andermann and Andermann, 1992; Saleh-el-Hilu, 1990). The birth of these children in some cases has made their mothers scapegoat in the family (Narayana, L, 1967; Lala and Samant, 1974). A recent study reported that all children with epilepsy had significant social deficits, boys with epilepsy had limited peer group activities and parents conferred fewer responsibilities to such children as compared to non-epileptic controls (Pal, Chaudhary, Sengupta, Das; 2002).

Various other behaviors associated with these reactions are ostracism, permissiveness and alteration in family activities, especially in leisure time activities and decreased parental expectations from the child with epilepsy (Ferrari et al, 1983).

Ritchie (1981) reported that mothers were more dominant in families where epilepsy is present, than in non-epileptic (control) families and that the epileptic child with epilepsy had a reduced level of involvement in family interactions as compared with control children, which may be detrimental to child's social development.

It is reported that families in which a member was diagnosed as having epilepsy, were concerned about the impact of the diagnosis on siblings. Parents were 
also worried about possible stresses on themselves. Hoare et al (1991) reported that siblings in families with a child suffering from chronic epilepsy were more disturbed than siblings in a control group or in families with a newly diagnosed epileptic child.

Summing up the factors affecting children with epilepsy, Schneider et al (1980) highlight that these myriad of psychological, psychosocial and medication factors impinge upon the child with epilepsy and may affect the adequacy of the child's development and neuropsychological functioning.

\section{Psychiatric morbidities:}

Much of literature focuses on seizures and their association to psychiatric and psychological morbidities. Flor-Henry (1976) reported that affective disorders were more commonly associated with right temporal lobe lesions than with left temporal lobe lesions. Deepened emotionality is reported to be associated with seizure disorder (Bear et al, 1982; Blumer, 1982; Aird et al., 1984; Sherwin, 1981).

Depression is also reported to be common (Trimble, 1985; Davis et al., 1984). The emotion of fear is also considered in the literature. Strauss et al (1982) reported that fear was the most common experienced emotion and that persons with left temporal lobe epilepsy had more social and sexual fear than did "normals" .

Evidence suggests that stress or emotional agitation experienced by persons with epilepsy can precipitate the onset or increase the frequency of seizures (Pond, 1981; Williams; 1981 ; Betts, 1983; Jacoby, 1992).

Having narrated the psychosocial difficulties that persons with epilepsy confront, in order to help them lead an effective and enriched life, a few intervention perspectives are described below.

\section{Psychosocial Intervention:}

\section{Quality of Life Model:}

Hartshorn \& Byers (1992) conceived the quality of life model. According to them, quality of life is understood in 5 domains viz., health, social/community and civic living, economic, personal development and family life. All these domains to gether explain quality of life and these various domains interact and exert influence on each other, as shown in the diagram below:

Based on the above model, interventions have been suggested (inputs in all the domains). 
1. Health:

- Help the patients to decrease their anxiety

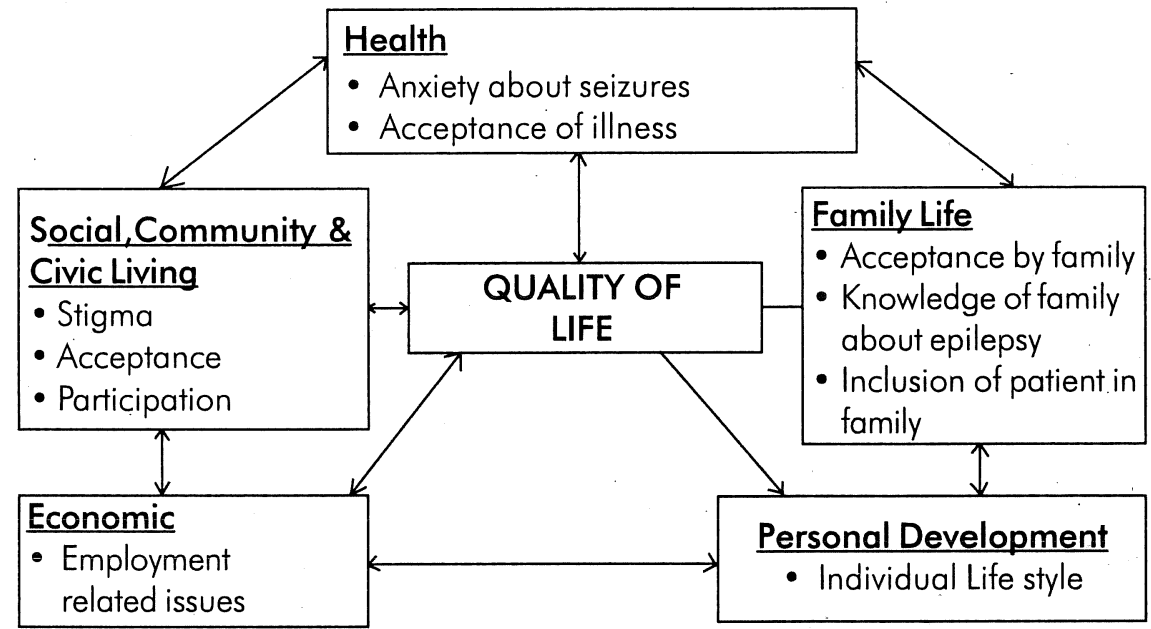

- Teach the patient to monitor side-effects of the drugs

- Tackle negative emotions associated with seizures

2. Family Life:

- Involve family in patient care

- Educate the family members about the disorder, its prognosis, need for treatment

- Encourage family to participate in support group

- Deal with family members' responses to the illness and facilitate their acceptance of the illness and the patient

- Sexual counseling to spouse

3. Social! community and civic activities:

- Encourage patient to participate in all the community activities

- Educate patient about insurance policies and other social security measures

- Educate and influence policy matters about epilepsy and its impacts on individuals.

4. Personal Development:

- Help patients to enhance coping 
- Help patients to identify factors that precede / precipitate seizures

- Help patients to make appropriate life style changes

\section{Economic:}

- Refer patients for vocational evaluation and intervention

\section{Seizure Management Programme: "Be Seizure Smart"}

Austin et al (2002) aimed at family interventions offering psycho-educational inputs for families of adolescents with epilepsy.

The study aimed at:

a. Providing information about epilepsy, treatment for seizure management

b. Addressing unique concerns and fears

c. Providing emotional support

The intervention study is based on a theoretical framework as shown below:

- Concerns/ fears about epilepsy

- Concerns abouthandling seizures

- Lack of knowledge about epilepsy

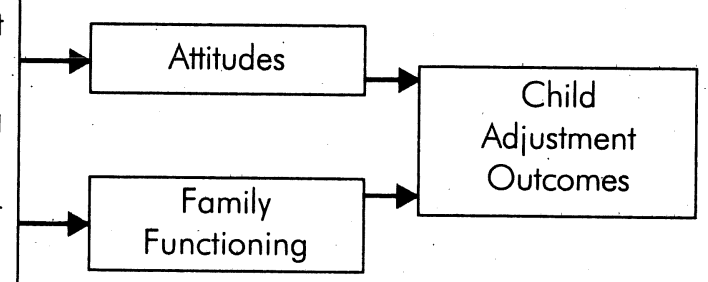

- Psychosocial care needs

"Be seizure smart" 
Intervention package based on the theoretical framework:

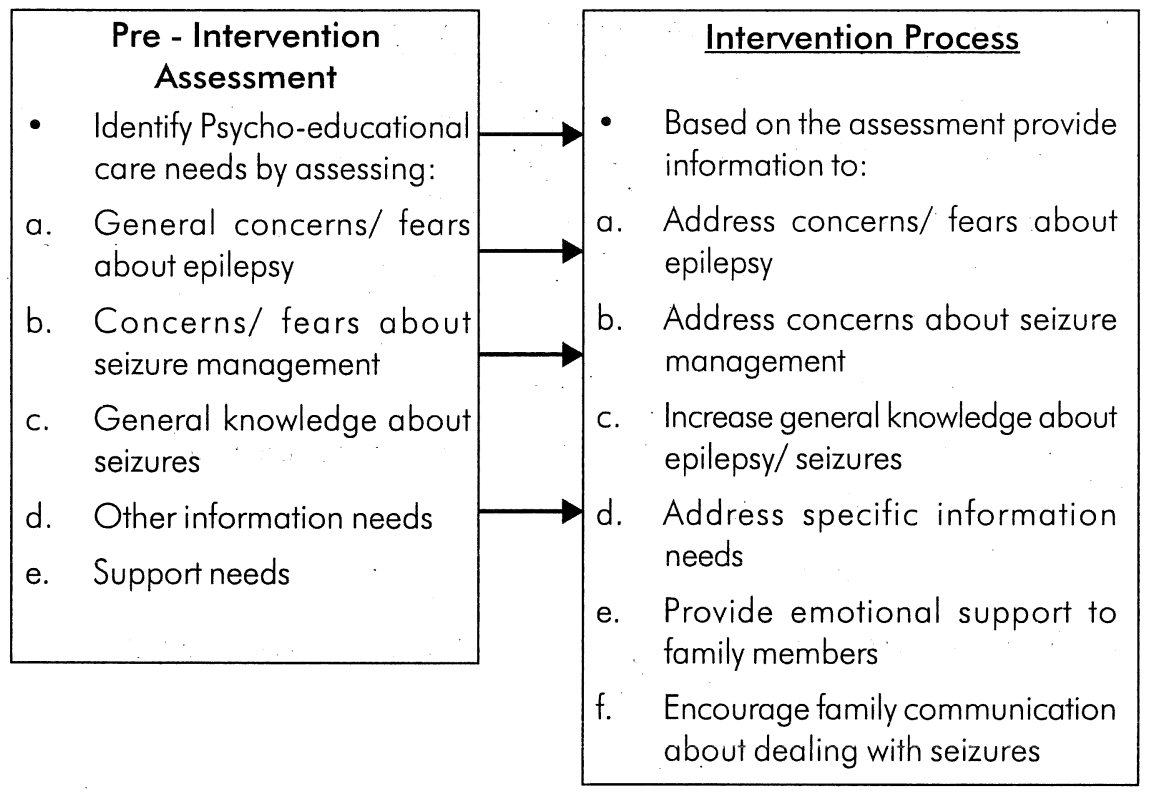

Results of the study showed that:

- Better understanding of the family about seizure

- Increased confidence of family members in managing seizures

- Improvement in functioning of the adolescent in the family

- Family expressed less support needs from professionals

\section{Further Interventions:}

The extensive review of literature shows that persons with epilepsy as well as their families have certain psychosocial needs like:

- Information needs

- Education about epilepsy

- Emotional support

- Vocational and rehabilitation needs

- Economic needs

- Family life and family adjustment needs 
- Need for social security and policies

- Need for professional support

\section{Partners in Psychosocial Care:}

In order to cater to the psychosocial needs of families and persons with epilepsy and for an efficient psychosocial care and management of their life, the following chart identifies the partners to work with.

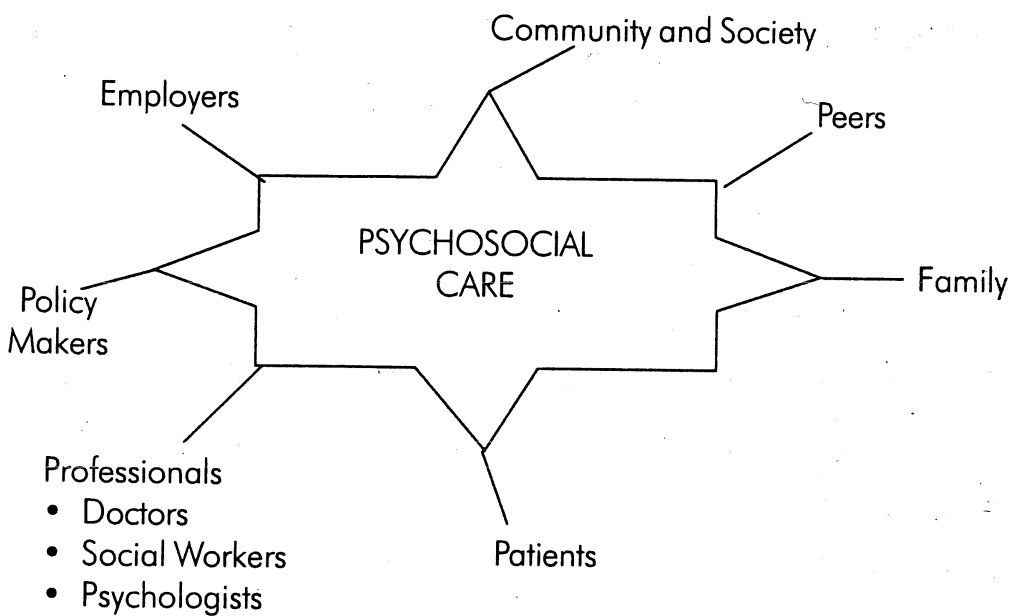

\section{Role of Social Work Profession:}

Professional social workers work with methods like casework, group work, community organization and social work research. The ultimate aim of such methods is to achieve better adaptation of oneself and his social environment.

In other words, the concern is restoration of impaired capacity, provision of individual and social resources and prevention of social dysfunction. Smith (1983) while commenting on social work with epileptic patients says, "because of many misconceptions that surround the term epilepsy, patients who have the illness often suffer emotional and physical anguish. Social workers have the responsibility to teach patients, families and the general public the truth about epilepsy and to fight for the rights of epileptic patients". Lala and Samanth (1974) conducted a study and assessed the need for social workers in epileptic clinic and found that most people felt that the role of a medical social worker as a member of the health team is highlighted in the total education process of the patient, family, staff and related to health agencies and professionals. 
Based on the experiences, lessons learnt and observations made, following suggestions can be made in order to further develop and concretize role of social work profession in working with epilepsy.

\section{Micro Level:}

1. Individual level:

- Using a case work approach, working with individuals can be focused on:

- Provide psycho-education to person suffering from epilepsy

- Intensive work with patients to help them accept their illness and make suitable life style changes

- Recognize the "abilities" rather than the "disabilities" of the patients and further enhance them.

- Adopting a supportive role with patients and families

- Linking individual patients to various community resources

2. Family level:

- Educating family members, helping them to accept the illness of the loved one

- Enhancing coping of the family members

- Empowering family members to communicate better, manage the patient's seizures and the associated disability

- Encourage family participation in care-giving

- Acknowledging family burden and care-giving and providing supportive and other services from the community

- Addressing the issue of stigma faced by the family

- Mobilization of resources to help family decrease their economic burden by informing about available social security measures like concessions

- Crises programs/services like telephone counseling

Working with groups has an advantage in terms of:

- Time and cost effectiveness

- Better outreach than working with individual

- Universalization, ventilation, acceptance and the reduction in stigma could be easily addressed in a group 


\section{Macro Level:}

At a macro level social work intervention would take form of "social action", mass education, awareness and advocacy.

- Social action - Social action programmes can create awareness about the need for medical treatment, social issues, myths associated with epilepsy. Carrying out such programs would educate employers to stop discriminating practices, sensitizing other authorities about problems faced by epileptics.

- Mass education - Social work can also aim at breaking the stereotypes of epileptic patients in the media. Social work professional can act as 'watch dogs' and see to it that the media coverage of health and mental health issues need to be less negative and less sensational and instead should be more towards promoting their life.

- Integration of mental health with primary care, as already proposed in the National Mental Health Program (1982) needs to be further emphasized. This could involve conducting community based health promotion and prevention program.

- Advocacy - Social work approach can also be used to advocate for the rights of persons with epilepsy, to frame new policies, prevent discrimination and stigmatization.

\section{Research:}

- Research on cultural influences on the management of epilepsy needs to be carried out

- Research will give indigenous data so that appropriate interventions can be planned

- There is paucity in the already conducted research on "strengths" of families, individuals, and communities. Identification of strength in relation to epilepsy can be of great benefit for planning interventions.

Though a lot of research / literature is generated on the psychosocial aspects of epilepsy, there are very few 'intervention' studies. Hence a need for more 'intervention studies' is also felt. 


\section{References:}

1. Aird RB, Masland RL, Woddyburry DM. The epilepsies: a critical review. New York: Raven Press, 1984.

2. Andermann and Andermann. University students with Epilepsy: A study of social aspects of seizure. Epilepsia, 1992; $1: 173-176$.

3. Austin J, Mc Neils A, Shore C, Dunn 0, Musick B. A feasibility study of a family seizure. Management program: Be seizure smart. Journal of Neuroscience Nursing, 2002; 34:30-38.

4. Baker GA, Brooks J, Buck, Jacoby A. The stigma of epilepsy: a European perspective. Epilepsia, 2000; 1:98-105.

5. Batzel KW, Dodrill CB. Neuropsychological and emotional correlates of marital status and ability to live independently in individuals with epilepsy. Epilepsia, 1984; 25:594-598.

6. Bear D, Levin K, Blumer D, Chetan D, Ryder J. Interictal behaviour in hospitalized temporal lobe epileptics: relationship to idiopathic psychiatric syndromes. Journal of Neurology, Neurosurgery, Psychiatry, 1982; 45:481 - 488.

7. Betts TA. The psychological management of epilepsy. In Rose FC, ed. Research progress in epilepsy. London: Atmon Books, 1983; 315-325.

8. Blumer P. Specific psychiatric complications in certain forms of epilepsy and their treatment. In: Sands H, ed. Epilepsy: a handbook for the mental health professional. New York: Bruner/Mazel, 1982; 97-110.

9. Chiou P. Comparison of Epilepsy and Asthama: Perceptions Among Preschool teachers in Taiwan. Epilepsia, 200; 5:647-651.

10. Collings. Psychosocial well-being and epilepsy: An empirical study. Epilepsia, $1992 ; 31: 418-426$.

11. Dansky LV, Andermann E, Andermann F. Marriage and fertility in epileptic patients. Epilepsia 1980; $21: 261-271$.

12. Davis GR, Armstrong HF, Donovan OM, Tenkes NR. Cognitive Behavioural Treatment of depressed affect among epileptics: preliminary findings. Journal of Clinical Psychology, 1984; 40:930-935.

13. Dodrill, David N, Geary B, Dubinsky B. Psychosocial problems among adults with epilepsy, 1984; 25:450-456.

14. Elwes J, Marshal A, Beattie K, Neuman. Epilepsy and Employment, a community based survey in an area of high unemployment. Journal of Neurology, Neurosurgery, Psychiatry, 1991, 54:200-203.

15. Ferrari M, Mathews, Barbara. The family and the child with epilepsy. Family Processes, 1983; 22:53-59. 
16. Flor-Henry P. Lateralized temporal limbic dysfunction and psychopathology. Ann New York Academic Science, 1976; 280:777-797.

17. Ford CA, Gibson P, Dreifuss FP. Psychosocial consideration in childhood epilepsy. In Dreifuss: Paediatric epileptology. Boston: John Wright 1983; 277. 295.

18. Gourie Devi, Rao VN, R Prakashi. Neuro epidemiological study in semi urban and rural areas in South India: patterns of neurological disorders including Motor Neuron Disease, 1987; 11 -22.

19. Gupta B, Yadav. Social adjustment of 116 adult epileptics. Indian Journal of Psychiatry, 1981; 22:271-273.

20. Hartshorn J, Byers V. Impact of Epilepsy on Quality of Life. Journal of Neuroscience Nursing 1992; 24:24-29.

21. Hatz. Impact of epilepsy on quality of life. Journal of Neuroscience Nursing, 1992; 23:24-29.

22. Heisler AB, Friedman SB. Social and psychological considerations in chronic disease: with particular reference to management of seizure disorder. Journal of Paediatric Psychology, 1981; 6:239-250.

23. Hoare BP, Whitman S, Wyler R Psychosocial predictors of psychopathology in epilepsy. British Journal of Psychiatry, 1991; 156-198.

24. I.C.M.R Collaborative study on severe mental morbidity, Delhi, 1987.

25. Indian Epilepsy Association 'Medical and Social Aspects of Epilepsy' I.E.A; Bangalore, 1992.

26. Jacoby A. Epilepsy and the quality of every day life: Findings from a study of people with well controlled epilepsy. Social Science Medicine, 1992; 657-666.

27. Lala VM, Samant JM. The role of Social Worker in an epilepsy clinic, Neurology India, 1974; 21:23-29.

28. Lechtenberg R, Akner L. Psychologic adaptation of children with epilepsy in a parent. Epilepsia, 1984; 25:40-45.

29. Max G. Psychotherapy with epileptic patients. In: Canger R, Angelerei F, Penry $\mathrm{JK}$, eds. Advances in epileptology, 11 th epilepsy international symposium. New York: Raven Press, 1984; 179-183.

30. Mirnics Zs, Halasz. Adjustment and coping in epilepsy. Seizure, 2001; 10:181-187.

31. Narayana L. A study of social and psychological aspects of epilepsy, DM and SP Dissertation (unpublished), 1967. 
32. Ozuna J. Psychosocial aspects of epilepsy. Journal of Neurosurgical Nursing, $1979 ; 11: 242-246$.

33. Pai D, Chaudhary G, Sengupta S, Das T. Social Integration of children with epilepsy in rural India. Social Science and Medicine, 2002; 54:1867-1874.

34. Parthasarthy R, Janardhana N. Psychosocial problems of people with epilepsy: Implications for professional social work services. Contemporary Social Work, 2002; 14:23-37.

35. Pond D. Psychosomatic aspects of epilepsy. In: Rose FC, ed. Research progress in epilepsy: London: Atmon Books, 1981; 175-180.

36. Ritchie K. Research note interaction in the families of epileptic children. Journal of Child Psychology, Psychology and Psychiatry, 1981; 22:65-71.

37. Saleh-El-Hilu. Social aspects of epilepsy in Kuwait. International Journal of Social Psychiatry, 1990; 36:68-73.

38. Schneider JW, Conrad P. In the closet with illness: epilepsy, stigma potential and information control. Social Problems, 1980; 28:32 - 44.

39. Shaw EB. Resources availed to the patient with epilepsy. In: Browne TR, Feldman RG. Epilepsy: diagnosis and management. Boston: Little Brown, 1983; 139. 143.

40. Sherwin I. Psychosis associated with epilepsy: significance of the laterality of the epileptic lesion. Journal of Neurology, Neurosurgery, Psychiatry, 1981 ; 44:83-85.

41. Smith L. Social Work with epileptic patients. In Turner J, eds. Differential Diagnosis and Treatment in Social Work, ed. Turner, London. The Free Press, 1983.

42. Smith, Dewey B. Jacob A, Chadwick. Seizure frequency patients perceived severity and the psychological consequences of intractable epilepsy. Epilepsy Research, 1991; 9:231-241.

43. Strauss $E$, Risser $A$, Jones MW. Fear responses in patients with epilepsy. Archives of Neurology, 1982; 39:626-630.

44. Trimble MR. Psychosomatic aspects of epilepsy. Advanced Psychological Medical Psychiatry, 1985; 13:133-150.

45. Williams D. The emotions and epilepsy. In Reynolds EH, Trimble MR, eds. Epilepsy and Psychiatry. Edinburgh: Churchill Livingstone, 1981, 49-59.

46. Woodward ES. The total patient: implications for nursing care of the epileptic. Journal of Neurosurgical Nursing, 1982; 14:166-169.

47. Zeigler RG. Epilepsy: Individual illness, human predicament and family dilemma. Family Relations, 1982;31:435-444. 